\title{
EVALUATION OF STATIC WORK CAPABILITIES \\ IN A HOT ENVIRONMENT
}

Robert E. Schlege1

School of ,Industrial Engineering

University of Oklahoma

Norman, Oklahoma

\section{ABSTRACT}

\begin{abstract}
The effects of heat stress on an individual's static work capabilities were investigated. Various indicators of strength and endurance were measured under differing heat stress levels. One measure which exhibited a significant change at higher heat stress levels was a combined strength-endurance measurement involving a series of maximal voluntary contractions throughout a one hour exposure. At $35^{\circ} \mathrm{C}$ WBGT the decrease in MVC from the beginning of the exposure to the end was $43 \%$ compared to only $6 \%$ at $18^{\circ} \mathrm{C}$ WBGT. Core temperature was also monitored throughout each exposure.
\end{abstract}

\section{INTRODUCTION}

In analyzing any physical work task, it is of ten convenient to partition the task into static and dynamic components even though the components may not be clearly distinguishable. This can help in evaluating the match between the task requirements and the individual's capabilities. The static components are those which involve little or no movement of the muscles or joints and the dynamic components are those involving alternate contraction and relaxation of the muscles.

The physiological changes associated with the two types of work differ. With static work, constriction of the blood vessels causes a reduced blood flow to the working muscles resulting in an increased blood pressure and a slight$1 y$ increased heart rate. With dynamic work, the pumping action of the muscles assists the flow of blood resulting in only a small change in blood pressure. There is, however, a greatly increased heart rate to satisfy the greater demands for fuel and oxygen.

Depending on the type of work, different measures of an individual's work capability can be used. For dynamic work, the efficiency of oxygen transport and utilization can be measured by maximal aerobic power. For static work, maximum voluntary contraction can be used as a measure of muscular strength and continuous hold endurance as a measure of muscular endurance.

In evaluating an individual's work capabilities, it is essential to know how they depend on the work environment. One aspect of the work environment is the level of heat stress. A large amount of data has been collected on the effects of heat stress on the performance of dynamic work but very little on the effects on static work. The recommended standards set forth in the NIOSH Criteria Document (NIOSH, 1976) are for tasks with a moderately high metabolic load. The objective of the standard is to maintain the core temperature within the Upper Limit of the Prescriptive Zone.

\section{LITERATURE REVIEW}

Research on static work tasks performed in hot environments has been limited and very general in nature. A study by Robbins (1942) indicated that grip strength decreased after a hot shower. Wright (1959), in investigating the relationship of grip strength to time of day, found that grip strength followed the same diurnal variation as core temperature. However, Tornval1 (1963) found no relationship between strength and time of day when examining the elbow flexors and knee extensors.

More controlled experiments have been performed by placing the limb in a hot water bath and examining changes in strength and endurance as a function of bath temperature and muscle temperature. Nukada (1955) investigated grip strength and endurance for water bath temperatures ranging from $20^{\circ} \mathrm{C}$ to $40^{\circ} \mathrm{C}$ and found that endurance was higher at the lower water temperatures and decreased steadily as water temperature increased. Grose (1958) used a water bath at $48^{\circ} \mathrm{C}$ for eight minutes and found an insignificant strength decrease but a $34 \%$ decrease in endurance.

A. R. Lind and associates (1957, 1958, 1959) investigated several combinations of water bath temperature and rest interval between tests using continuous hold endurance at $1 / 3$ MVC. The results showed little changes in strength but up to an $80 \%$ change in endurance from the lower to the higher bath temperatures. The effect was attributed to a shift in the blood flow from the muscles to the limb surface to aid in cooling.

\section{EXPERIMENT}

\section{Objective}

The objective of the current research was to evaluate changes in strength and endurance resulting from an overall hot environment rather than a water bath. The approach was to expose the subject to fixed heat stress levels and while monitoring core temperature and other

Copyright (C) 1979, The Human Factors Society, Inc. All rights reserved. 
parameters make measurements of strength and endurance. For preliminary work, grip strength measurement was selected as it appeared to be the most promising and allowed for comparisons with previous findings.

\section{Variables}

For the preliminary study, a combined measure of strength and endurance was used. It consisted of a series of five-second maximal voluntary contractions taken every thirty seconds while in the heat stress environment. This combined strength-endurance measure was selected to provide preliminary evaluation of the cumulative effects of repeated strength measurement under different heat stress levels. It provided an indication of the degree of fatigue involved and the adequacy of recovery time for repeated static exertions.

Each trial consisted of a sixty minute exposure to one of three heat stress levels. The heat stress levels used were $18^{\circ} \mathrm{C}, 26.5^{\circ} \mathrm{C}$ and $35^{\circ} \mathrm{C}$. The relative humidity for all exposures was $40 \%$.

Two females, ages 20 and 26 , were used as subjects. Neither subject was acclimatized, but both were experienced in performing static strength exertions. Each subject was exposed to each environment twice and the order of exposures was counterbalanced.

Each MVC measurement consisted of a five second exertion measured in accordance with the recommended guidelines for strength measurement given by Kroemer (1970), Caldwell et al. (1974) and Chaffin (1975). In addition, core temperature was monitored continuously during the exposure.

\section{Apparatus}

The major pieces of equipment were those used to perform the strength measurements. A special apparatus was constructed to measure grip strength using a strain gage force transducer. The signal from the load cell was conditioned by a preamplifier and amplifier, recorded on a strip chart recorder and input to a PDP 11/03 minicomputer via an analog-to-digital converter. The computer system sampled the incoming data at the rate of twenty points per second, calculated the maximum twenty point moving average and output the strength value for each exertion. The computer also controlled the timing of the experiment and provided signals to cue the subject for each force exertion.

Standard WBGT apparatus was used to monitor the heat stress level and a rectal thermistor probe inserted $10 \mathrm{~cm}$ beyond the anal sphincter was used to monitor core temperature.

\section{RESULTS}

For each trial, the data consisted of a set of 120 MVC values. Due to the wide variation between successive points, some type of smoothing was required. The technique used was to calculate the average of every five successive points, thus giving a single value for each 2.5 minute period. This reduced the amount of data to 24 points for each 60 minute trial.

Figures 1,2 and 3 show the results obtained at $18^{\circ} \mathrm{C}, 26.5^{\circ} \mathrm{C}$ and $35^{\circ} \mathrm{C}$ WBGT respectively. The values are the combined averages of both subjects across all trials. At $18^{\circ} \mathrm{C}$ WBGT, the MVC showed a slight decrease from $14.5 \mathrm{~kg}$ initially to $13.6 \mathrm{~kg}$ after 60 minutes. At $26.5^{\circ}$ $\mathrm{C}$, there was a more significant decrease from 15.2 to $11.8 \mathrm{~kg}$ and at $35^{\circ} \mathrm{C}$ a pronounced decrease from 18.8 to $10.4 \mathrm{~kg}$. For the three heat stress levels the percentage decreases were $6 \%$, $23 \%$ and $43 \%$ respectively.

Figure 4 shows the results for all three heat stress levels. There is a significant difference in muscular endurance dependent on the temperature of the environment. As the heat stress level increases, the initial strength also increases. However, the decline in strength after a continuous exposure is also greater under the higher levels of heat stress. A least squares regression analysis was performed on the reduced data with the following results.

For $18.0^{\circ} \mathrm{C}$ : Force $(\mathrm{kg})=14.10-0.014 \times$ Time $(\min )$

For $26.5^{\circ} \mathrm{C}$ : Force $(\mathrm{kg})=15.20-0.054 \times$ Time $(m i n)$

For $35.0^{\circ} \mathrm{C}$ : Force $(\mathrm{kg})=18.78-0.136 \times$ Time $(\min )$

The correlation coefficients for the above analysis were $-0.27,-0.74$ and -0.93 respective$1 \mathrm{y}$.

The changes in core temperature are given in Table 1. The core temperature data followed the same pattern for both subjects. In the 18 and $26.5^{\circ} \mathrm{C}$ environments there was a slight decrease $\left(0.2^{\circ} \mathrm{C}\right)$. At $35^{\circ} \mathrm{C}$, the core temperature increased approximately $0.5^{\circ} \mathrm{C}$ during the one hour exposure.

Table 1: Average core temperature for all trials at the beginning, middle and end of each exposure. $\underset{\text { WBGT }}{\text { Environment }}$

18.0

26.5

35.0

\begin{tabular}{lll}
$\begin{array}{c}\text { Core } \\
0 \mathrm{~min}\end{array}$ & $\begin{array}{c}\text { Temperature } \\
30 \mathrm{~min}\end{array}$ & $\begin{array}{c}{ }_{\mathrm{C}} \\
60 \mathrm{~min}\end{array}$ \\
\hline 37.00 & 36.85 & 36.80 \\
37.40 & 37.23 & 37.20 \\
37.35 & 37.50 & 37.83
\end{tabular}




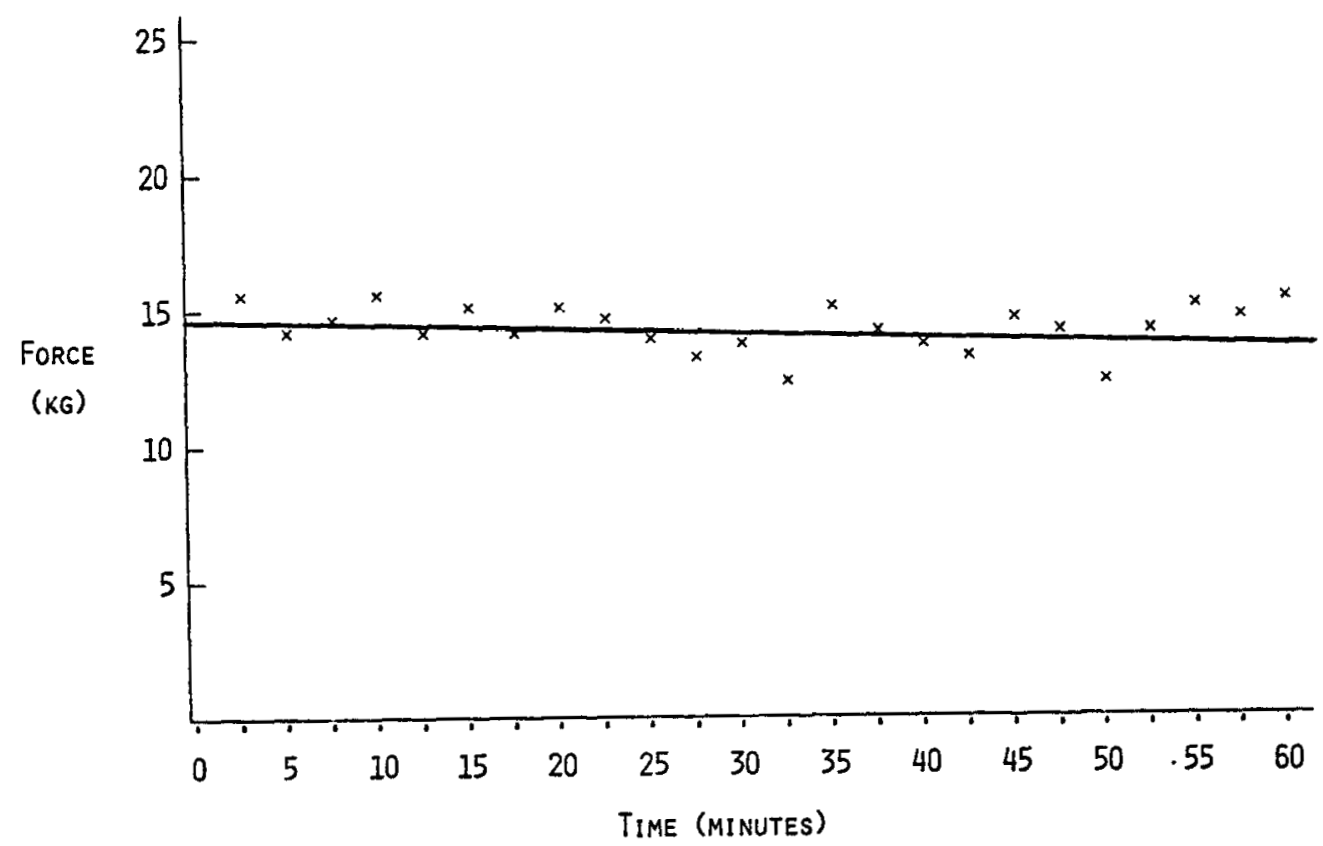

Figure 1. MVC Force vs. Time at $18.0^{\circ} \mathrm{C}$ WBGT

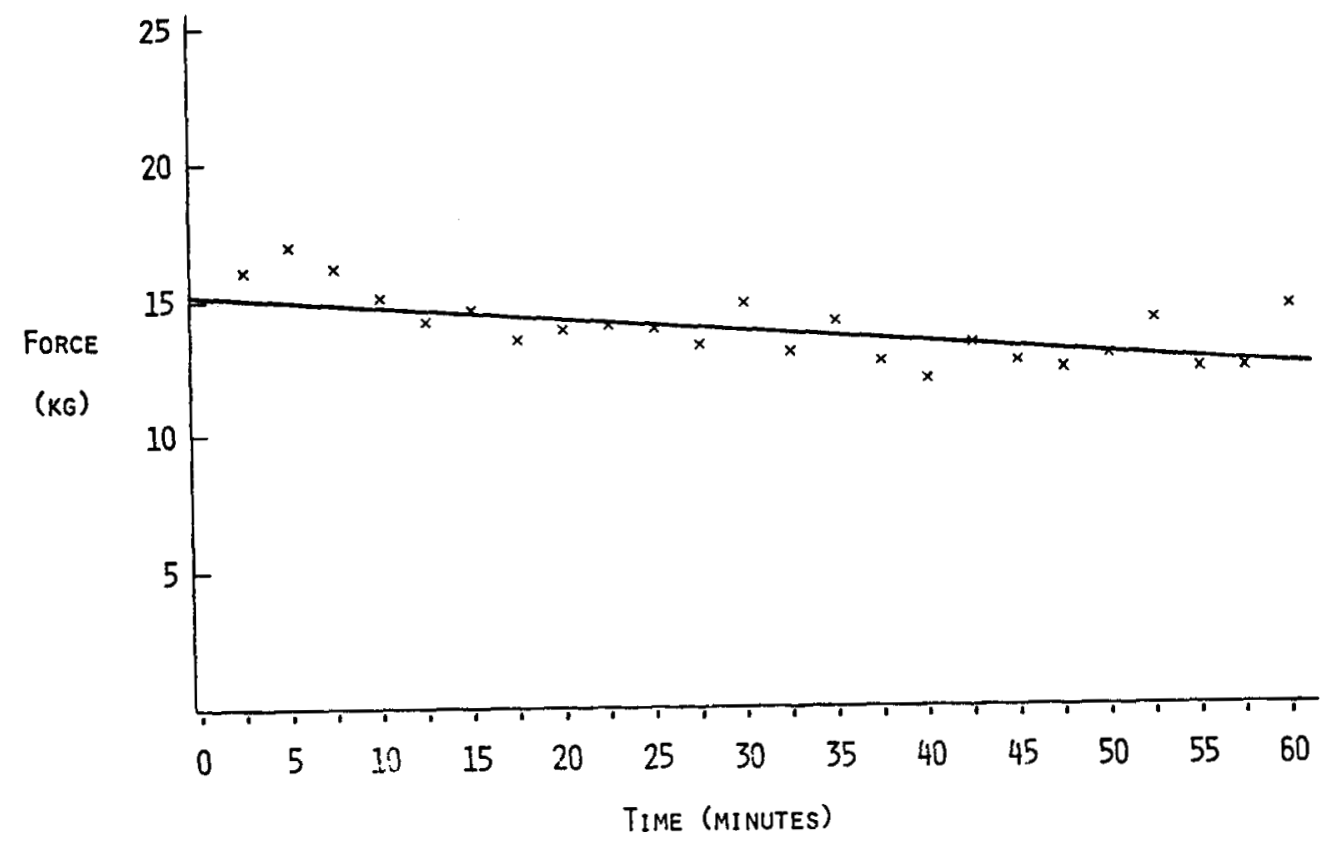

Figure 2. MVC Force vs. Time at $26.5^{\circ} \mathrm{C}$ WBGT 


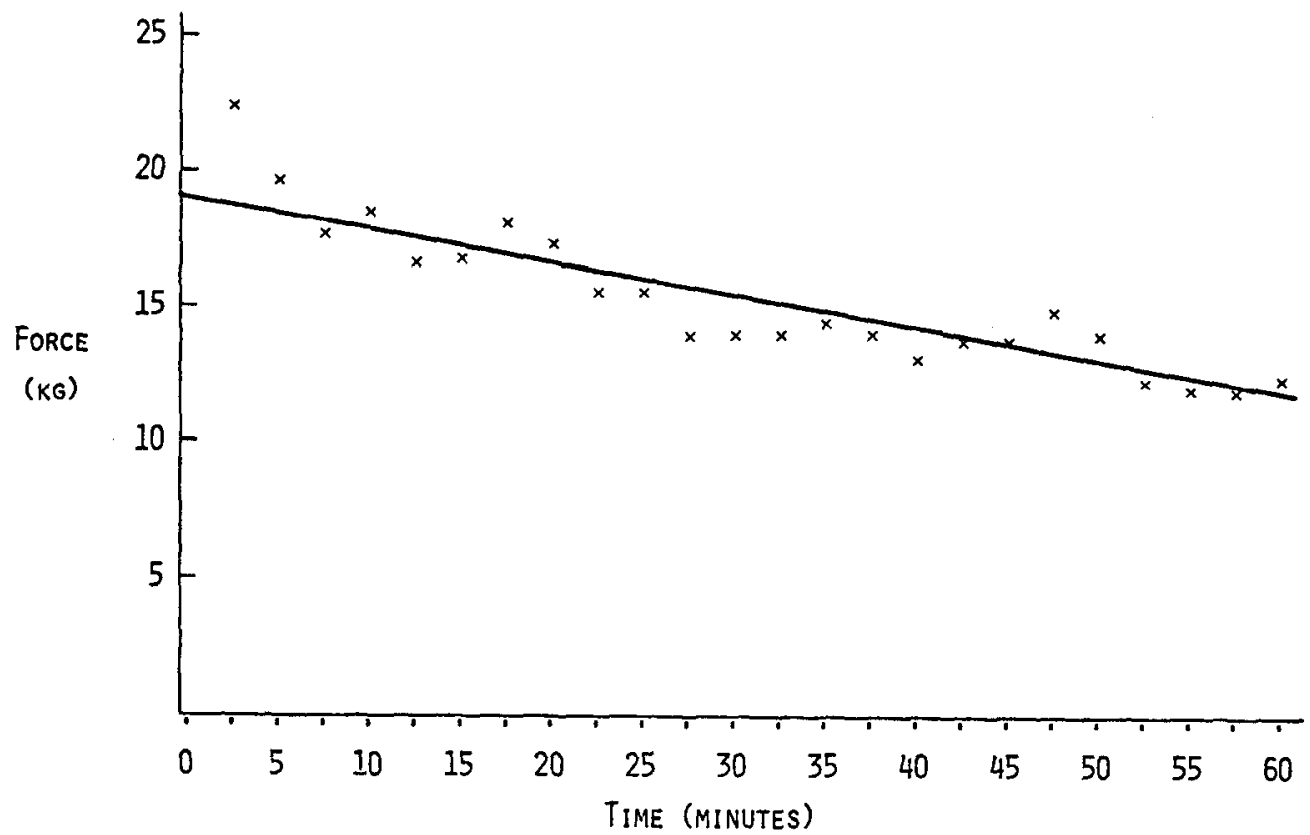

Figure 3. MVC Force vs. Time at $35.0^{\circ} \mathrm{C}$ WBGT

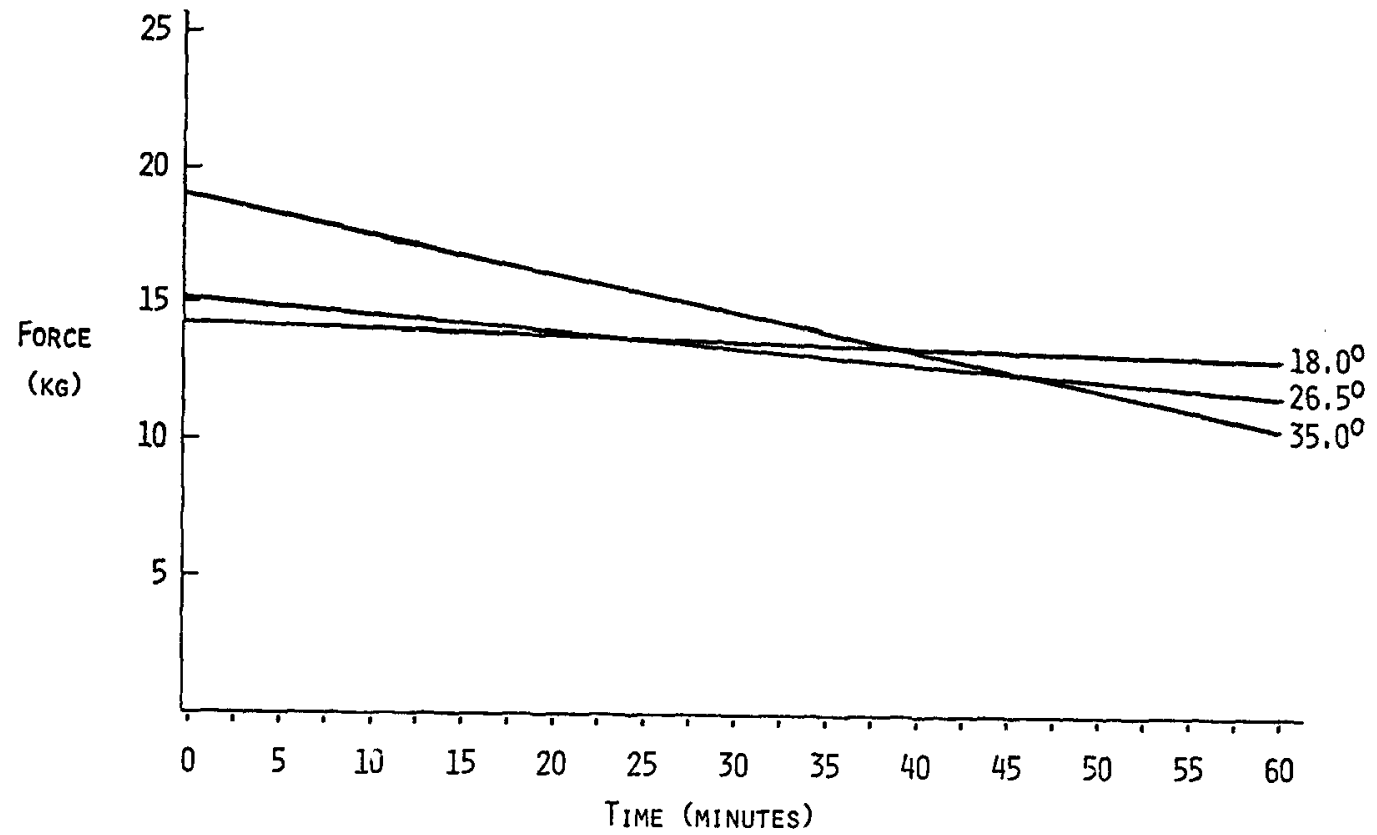

Figure 4. MVC Force vs. Time at $18.0^{\circ}, 26.5^{\circ}$ and $35.0^{\circ} \mathrm{C}$ WBGT 


\section{SUMMARY}

In evaluating the effects of heat stress on static work capabilities, it is evident that the heat stress level has a definite effect on how rapidly one fatigues when required to repeatedly exert his maximum strength. For the $18^{\circ} \mathrm{C}$ level, it appears that the 25 second recovery time is adequate. At $26.5^{\circ} \mathrm{C}, 25$ seconds appears questionable while at $35^{\circ} \mathrm{C}$ it is completely inadequate. The results agree with the previous experimentation performed by immersing the forearm in a hot water bath in that endurance decreases with higher temperatures.

The pattern of results for both subjects were similar. For almost all trials, a cyclic pattern was evident in the data. Although the reason for this cycling was not obvious, it is hypothesized to be the result of fluctuations in the level of motivation.

These preliminary results are part of a larger study examining various aspects of static work in hot environments. Additional data is forthcoming on the separate effects of heat stress on strength and continuous hold endurance. The larger study involves additiona1 subjects, both acclimatized and unacclimatized, working in environments which result in higher core temperatures.

\section{REFERENCES}

Caldwe11, L.S., Chaffin, D.B., Dukes-Dobos,F.N., Kroemer, K.H.E., Laubach, L.L., Snook, S.H. and Wasserman, D.E., "A Proposed Standard Procedure for Static Muscle Strength Testing," American Industrial Hygiene Association Journa1, 35(4), 201-206, 1974.

Chaffin, D.B., "Ergonomics Guide for the Assessment of Human Static Strength," American Industrial Hygiene Association Journal, 36(7), 505-511, 1975.

Clarke, R.S.J., Hellon, R.F. and Lind, A.R., "The Duration of Sustained Contractions of the Human Forearm at Different Muscle Temperatures," Journal of Physiology, 143, 454-473, 1958.

Grose, J.E., "Depression of Muscle Fatigue Curves by Heat and Cold," Research Quarterly, $29(1), 19-31,1958$.

Kroemer, K.H.E., "Human Strength: Terminology, Measurement, and Interpretation of Data," Human Factors, 12(3), 297-313, 1970.

Lind, A.R., "Muscle Fatigue and Recovery from Fatigue Induced by Sustained Contractions," Journal of Physiology, 147, 162-171, 1959.

Lind, A.R. and Samueloff, M., "The Influence of Local Temperature on Successive Sustained Contractions," Journal of Physiology, 136, 12-13P, 1957.
National Institute for Occupational Safety and Health (NIOSH), Standards for Occupational Exposures to Hot Environments, Proceedings of Symposium, February 27-28, Pittsburgh, Pennsylvania, Horvath, S.M. and Jensen, R.C., Eds., U.S. Department of Health, Education and Welfare, Publication Number 76-100, 1976.

Nukada, A., "Hauttemperatur und Leistungsfahigkeit in Extremitaten bei Statischer Holtearbeit," Internationale Zeitschrift fur Angewancte Physiologie einschleisslich Arbeitsphysiologie, 16, 74-80, 1955.

Robbins, A.c., "The Effects of Hot and Cold Shower Baths Upon Adolescents Participating in Physical Education Classes," Research Quarterly, 13, 373-380, 1942.

Tornval1, G., "Assessment of Physical Capabilities with Special Reference to the Evaluation of Maximal Voluntary Isometric Muscle Strength and Maximal Working Capacity, An Experimental Study on Civilian and Military Subject Groups," Acta Physiologica Scandioavica, 58(Supp1. 201), 32, 1963.

Wright, V., "Factors Influencing Diurnal Variation of Strength of Grip," Research Quarterly, $30,110-116,1959$. 